\title{
Detection of eicosanoids in epiretinal membranes of patients suffering from proliferative vitreoretinal diseases
}

\author{
Albert J Augustin, F H Grus, F Koch, M Spitznas
}

\begin{abstract}
Aim-Arachidonic acid is metabolised via lipoxygenase to 15-HETE (15hydroxyeicosatetraenoic acid) and 15HPETE (15-hydroperoxyeicosatetraenoic acid), which are believed to influence proliferation in tissue culture. 15-HETE is the reduction product of 15-HPETE. Cell proliferation is believed to be decreased by 15-HPETE and increased by 15-HETE. The aim of this study was to investigate epiretinal membranes for the presence of these lipoxygenase products and to compare membranes from different disease processes.
\end{abstract}

Methods-Epiretinal membranes of 15 patients suffering from proliferative vitreoretinopathy (PVR, $\mathbf{n = 7 )}$ and proliferative diabetic retinopathy (PDR; $n=8)$ were removed during vitrectomy and analysed by means of thin layer chromatography. The plates were evaluated by digital image analysis.

Results-Both 15-HETE and 15-HPETE were identified in membranes from eyes of patients with PVR and PDR with HETE values significantly higher $(p<0.05)$ than HPETE values (HETE/HPETE ratio = 5.2).

Conclusion-This study demonstrates that eicosanoids are present in the epiretinal membrane tissue of patients with PVR and PDR. Considering that HETE increases cell proliferation while HPETE inhibits it, it is conceivable that eicosanoids are an additional factor contributing to the regulation of membrane growth in proliferative retinal disorders. Thus, inhibition of lipoxygenase could be a therapeutic approach in these diseases. (Br f Ophthalmol 1997;81:58-60)

Several growth factors and metabolites of the arachidonic acid pathway such as prostaglandins are known to be involved in the pathogenesis of proliferative diabetic retinopathy (PDR). ${ }^{1}$

Retinal pigment epithelial cells, breakdown of the blood-retinal barrier with subsequent phagocyte invasion, and various mediators of inflammation are involved in membranogenesis in proliferative vitreoretinopathy (PVR), believed to be the result of aberrant wound healing. ${ }^{2-5}$ Inflammation is known to be a prerequisite to healing.

The metabolites of the arachidonic acid cascade are known to influence cell growth and the regulation of cell behaviour such as adhesion and migration..$^{6-8}$

While results of cyclo-oxygenase inhibitors were contradictory, lipoxygenase inhibitors decrease cell growth in vivo. Additionally, lipoxygenase products show differential effects on cell growth. Cell proliferation is decreased by $15-$ HPETE (15-hydroperoxyeicosatetraenoic acid) and increased by 15-HETE (15-hydroxyeicosatetraenoic acid). ${ }^{710}$

The aim of this study was to investigate epiretinal membranes for the presence of these lipoxygenase products and to compare membranes from different disease processes.

\section{Methods}

Epiretinal membranes of 15 patients suffering from proliferative vitreoretinopathy (PVR; $n=$ 7) and proliferative diabetic retinopathy (PDR; $\mathrm{n}=8$ ) were removed during vitrectomy, transferred to an eppendorf cap, snap frozen using liquid nitrogen, and immediately stored at $-70^{\circ} \mathrm{C}$.

The membranes were homogenised using an Ultra Turrax blender (Janke \& Kunkel, Staufen, Germany) and extracted in $0.3 \mathrm{ml}$ hexane/ether $(1: 1 \mathrm{v} / \mathrm{v})$. Thereafter, $0.3 \mathrm{ml}$ of hexane/ether $(1: 1 \mathrm{v} / \mathrm{v})$ was added and the samples were centrifuged for 15 minutes at 18000 $g\left(4^{\circ} \mathrm{C}\right)$. The supernatants were evaporated to dryness under nitrogen. The dried samples were redissolved in $100 \mu \mathrm{l}$ chloroform/ methanol $(2: 1 \mathrm{v} / \mathrm{v})$. Thereafter, thin layer chromatography was performed at $0^{\circ} \mathrm{C}$ using Merck HPTLC silica gel 60 F254 (Merck, Darmstadt, Germany) with a mobile phase of ether/hexane/chloroform (60:40:1 v/v). For identification of arachidonic acid, 15-HETE, and 15-HPETE external standards (Biomol, Hamburg, Germany) were used. Plates were sprayed with $50 \% \mathrm{H}_{2} \mathrm{SO}_{4}$ and heated at $113^{\circ} \mathrm{C}$ for 13 minutes. Quantitative evaluation of the thin layer chromatography was performed by digital image analysis (ScanPacK; Biometra, Göttingen, Germany). Figure 1 is a photograph
Accepted for publication 14 October 1996 


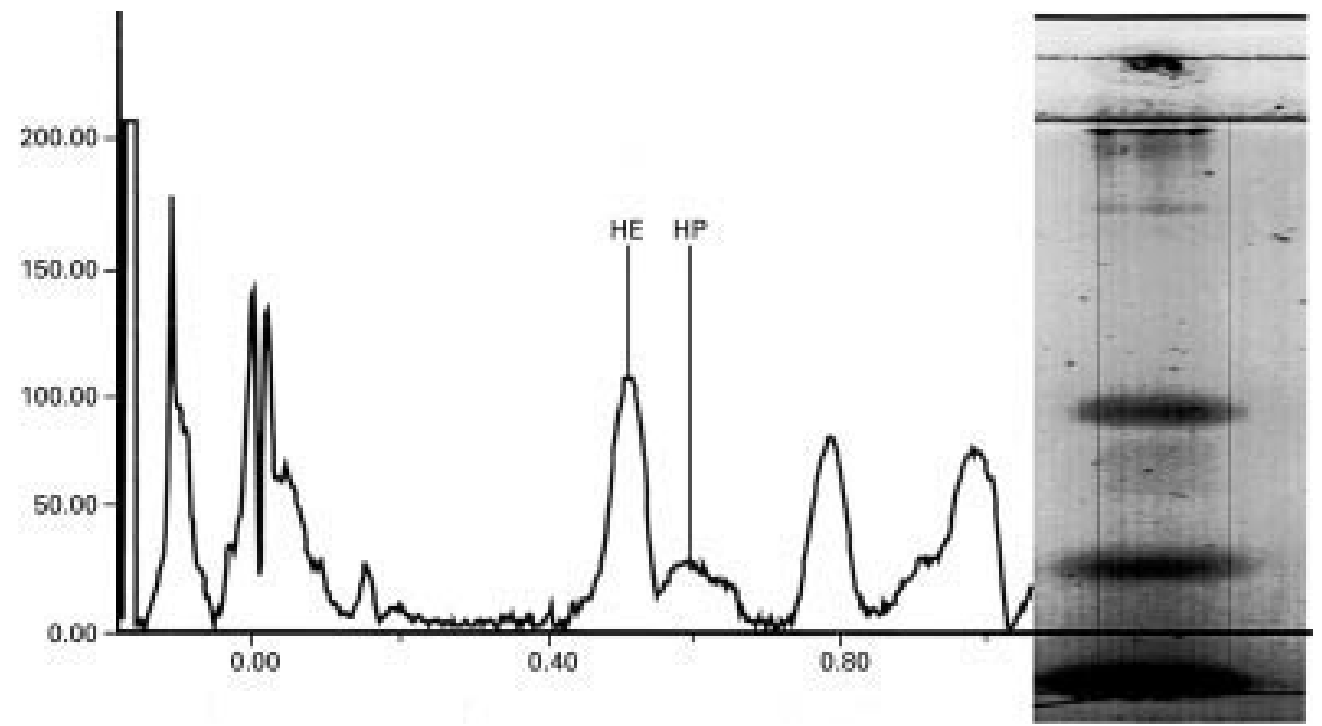

Figure 1 Photograph and densitograph of a PVR membrane with 15-HETE (HE) and 15-HPETE (HP).

and typical densitograph of a PVR membrane with 15-HETE and 15-HPETE bands. Statistical analysis was performed using Student's $t$ test.

\section{Results}

Both 15-HETE and 15-HPETE were identified in epiretinal membranes from patients with PVR and PDR by means of thin layer chromatography. The HETE values were significantly higher $(\mathrm{p}<0.05)$ than the HPETE values (HETE/HPETE ratio $=5.2$; Fig 2 ). This indicates that HPETE is metabolised to HETE in membrane tissue. There was no significant difference between PDR and PVR values.

\section{Discussion}

The pathogenesis of both proliferative diabetic retinopathy (PDR) and proliferative vitreoretinopathy (PVR) is still poorly understood. Retinal ischaemia/hypoxia is still considered the most important factor for the development of PDR, whereas the retinal pigment epithelium and breakdown of the blood-retinal

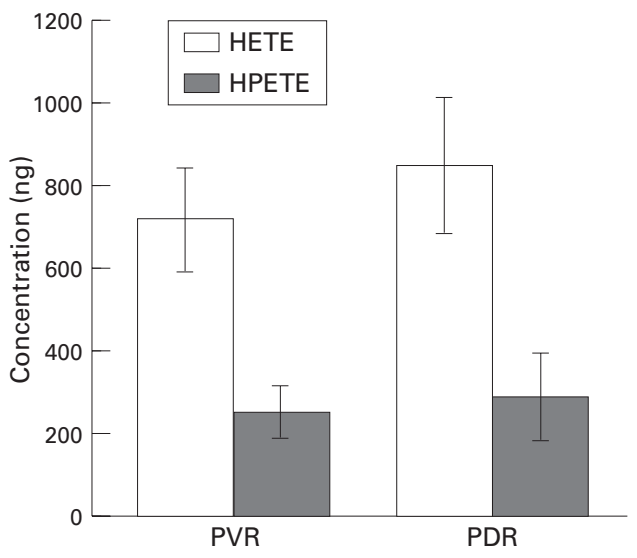

Figure 2 15-HETE and 15-HPETE values in epiretinal membranes from patients with proliferative diabetic retinopathy (PDR) and proliferative vitreoretinopathy (PVR). The HETE values were significantly higher ( $p$ $<0.05)$ than HPETE values (HETE/HPETE ratio $=$ 5.2). barrier are believed to be major factors leading to the development of PVR. In addition, several molecules and other cell types as well as oxidative reactions with subsequent inflammation could be identified as being involved in the disease processes of PDR and PVR. ${ }^{11}{ }^{12}$

Several cytokines and growth factors are believed to contribute to the pathogenesis of PDR. ${ }^{1314}$ Prostaglandins causing macrophage activation and inflammatory reactions as well as other cells of the immune system have been identified in PDR. ${ }^{15}$ Esser and coworkers demonstrated that macrophages from several subpopulations including inflammatory phase macrophages are present in membranes from PDR. ${ }^{16}$

In membranes removed from PVR eyes various cell types such as RPE cells and macrophages could be identified. ${ }^{31718}$ It could also be demonstrated that growth factors, prostaglandin E, complement, and cytokines originating from macrophages are able to induce inflammatory responses and are mitogenic. ${ }^{12-21}$ Thus, several inflammatory pathways such as the arachidonic acid pathway are activated. In the present study we found 15-HETE values being significantly higher than 15-HPETE values in the epiretinal membrane tissue of patients with PVR and PDR.

Considering that HETE increases cell proliferation while HPETE inhibits it, it is conceivable that lipoxygenase products are an additional factor contributing to the regulation of membrane growth in proliferative retinal disorders. The (anti-)proliferative effects have already been proved in other models and are believed to be due to the generation of free radicals by the hydroperoxide (HPETE) and mitogenic response by hydroxide (HETE). ${ }^{72223}$

The lipoxygenase inhibitor NDGA was shown to reduce cell growth in several different cell lines. ${ }^{24-26}$ Similarly, indomethacin, an inhibitor of the cyclo-oxygenase pathway, has a slight antiproliferative effect in proliferative retinal disorders. ${ }^{77}$ This seems to be contradictory because the production of prostaglandin 
$\mathrm{D}_{2}$ (PGD2), an antiproliferative metabolite of the cyclo-oxygenase pathway, is inhibited by indomethacin. ${ }^{26} 28$ However, cyclo-oxygenase inhibition also leads to higher HPETE values. This is believed to be the result of an increased shunt through the lipoxygenase pathway, thus resulting in reduction of cell proliferation by HPETE. Since, on the other hand, peroxidases, such as glutathione peroxidase and reduction equivalents (electrons), are present, HPETE is converted to HETE, resulting again in tissue proliferation. This fact helps to explain why indomethacin only exerts a slight effect on membrane growth. Thus, the inhibition of lipoxygenase, which prevents the production of HETEs, could be a promising new therapeutic approach in proliferative retinal disorders. Consecutive stimulation of cyclo-oxyenase could then lead to additional antiproliferative effects through the production of PGD2.

A part of this study was presented at the ARVO meeting, May A part of this study was presented at

This work was supported by 'Aktion Kampf der Erblindung' (AKDE).

1 Jampol LM, Ebroon DA, Goldbaum MH. Peripheral proliferative retinopathies: an update on angiogenesis, etiologies erative retinopathies: an update on angiogenesis, etio

2 Hui YN, Goodnight R, Sorgente N, Ryan SJ. Fibrovascular proliferation and retinal detachment after intravitreal injection of activated macrophages in the rabbit eye. $A m \mathcal{F O} \mathrm{Oph}$ thalmol 1989;108:176-84.

3 Jerdan JA, Pepose JS, Michels R, Hayashi H, Bustros S de, Sebag M, et al. Proliferative vitreoretinopathy membranes. An immunohistochemical study. Ophthalmology 1989;96: 801-10.

4 Weller M, Heimann K, Wiedemann P. The pathogenesis of vitreoretinal proliferation and traction: a working hypothesis. Med Hypoth 1990;31:157-9.

5 Wolter JR. The macrophages of the human vitreous. $A m \mathcal{F}$ Ophthalmol 1960;49:1185-93.

6 Honn KV, Timar J, Rozhin J, Bazaz R, Sameni M, Ziegler G, et al. A lipoxygenase metabolite, 12-(S)-HETE, stimulates
protein kinase C-mediated release of cathepsin B from malignant cells. Exp Cell Res 1994;214:120-30

7 Kumar YVK, Raghunathan A, Sailesh S, Prasad M, Vemuri Kumar YVK, Raghunathan A, Sailesh S, Prasad M, Vemuri MC, Reddanna P. Differential effects of 15-HPETE and
15-HETE on BHK-21 cell proliferation and macro15-HETE on BHK-21 cell proliferation and macromolecu

8 Matsumoto R, Naka M, Omawari N, Fujitani B, Aishita H. Effects of OP-41483.alpha-CD, a stable prostacyclin analog, on cultured endothelial cell dysfunction caused by 15 (S)-hydroperoxy-5,8,11,13-eicosatetraenoic acid (15HPETE) in vitro. Life Sci 1993;52:1257-64.

9 Liu B, Marnett LJ, Chaudhary A, Ji C, Blair IA, Johnson $\mathrm{CR}$, et al. Biosynthesis of 12(S)-hydroxyeicosatetraenoic acid by B16 amelanotic melanoma cells is a determinant of their metastatic potential. Lab Invest 1994;70:314-23.

10 Sandstrom PA, Tebbey PW, Van Cleave S, Buttke TM Lipid hydroperoxides induce apoptosis in T cells displaying a HIV-associated glutathione peroxidase deficiency. $\mathcal{F}$ Biol Chem 1994;269:798-801.

11 Augustin AJ, Breipohl W, Böker T, Spitznas M. Increased lipid peroxide levels and myeloperoxidase activity in the vitreous of patients suffering from proliferative diabetic retinopathy. Graefes Arch Clin Exp Ophthalmol 1993;231: $647-50$

12 Böker T, Augustin AJ, Breipohl W, Lutz J, Spitznas M. Increased lipid peroxide level and myeloperoxidase activity
in the vitreous of patients suffering from proliferative vitreoretinopathy. Graefes Arch Clin Exp Ophthalmol 1994; 232:652-6.

13 Aiello LP, Northrup JM, Keyt BA, Takagi H, Iwamoto MA. Hypoxia regulation of vascular endothelial growth factor in Hypoxia regulation of vascular endothelial grow
retinal cells. Arch Ophthalmol 1995;113:538-44.

14 Aiello LP, Avery RL, Arrigg PG, Keyt BA, Jampel HD, Shah ST, et al. Vascular endothelial growth factor in ocular fluid of patients with diabetic retinopathy and other retinal diseases. N Engl F Med 1994;331:1480-7.

15 Tang S, Scheiffarth OF, Thurau SR, Wildner G. Cells of the immune system and their cytokines in epiretinal membranes and the vitreous of patients with proliferative diabetic retinopathy. Ophthalmic Res 1993;25:177-85.

16 Esser P, Heimann K, Wiedemann P. Macrophages in proliferative vitreoretinopathy and prolfierative diabetic retinopathy: differentiation of subpopulations. $\mathrm{Br} \mathcal{F ~ O p h}$ thalmol 1993;77:731-3.

17 Hiscott PS, Grierson I, McLeod D. Retinal pigment epithelial cells in epiretinal membranes: an immunohistochemical lial cells in epiretinal membranes: an imm

18 Kampik A, Kenyon KR, Michels RG, Green WR, Cruz ZC de la. Epiretinal and vitreous membranes. Comparative study of 56 cases. Arch Ophthalmol 1981;99:801-10.

19 Heffernan JT, Futterman S, Kalina RE. Dexamethasone inhibition of experimental endothelial cell proliferation in retinal venules. Invest Ophthalmol Vis Sci 1978;17:565-8.

20 Leibovich SJ, Wiseman DM. Macrophages, wound repair and angiogenesis. Prog Clin Biol Res 1988;266:131-45.

21 Naveh N, Weissman C. Corticosteroid treatment of laser retinal damage affects prostaglandin $\mathrm{E}_{2}$ response. Invest Ophthalmol Vis Sci 1990;31:2508-13.

22 Calzada C, Rice-Evans C. Ruptured erythrocytes inhibit the oxidation of membranes by 15-hydroperoxyoxidation of membranes by 15-hydr

23 Onoda JM, Kantak SS, Piechocki MP, Awad W, Chea R, Liu $\mathrm{B}$, et al. Inhibition of radiation-enhanced expression of $\mathrm{B}$, et al. Inhibition of radiation-enhanced expression of
integrin and metastatic potential in B 16 melanoma cells by a lipoxygenase inhibitor. Radiat Res 1994;140:410-8.

24 Das UN. Selective enhancement of free radicals by cis-unsaturated fatty acids in tumor cells as strategy to kill tumor cells in vitro and in vivo. In: Reddy CC, Hamilton G, Madyastha K, eds. Biological oxidation systems, vol 2. San Diego, CA: Academic Press, 1990:607-24.

25 Postoak D, Nystuen L, King L, Ueno M, Beckman BS. 15-Lipoxygenase products play a role in proliferation of ransformed erythroid cells. Am f Physiol 1990;259:C84953.

26 Ralph RK, Wojcik S. Inhibitors of lipoxygenase have antiproliferative effects on P815 murine mastocytoma cells. antiproliferative effects on P

27 Blumenkranz MS, Ophir A, Claflin A, Hajek AS. Fluorouracil for the treatment of massive preretinal proliferation. Am f Ophthalmol 1982;94:458-67.

28 Masanori F, Takethosi K, Ryuzo U, Kazuo O, Shah N, Osamu H. Prostaglandin $\mathrm{D}_{2}$, a potential antineoplastic agent. Biochem Biophys Res Commun 1982;105:956-64. 